\title{
Aa. Vv., Vieillir à la Renaissance, textes réunis, présentés et édités par Colette H. Winn et Cathy Yandell
}

\section{Michele Mastroianni}

\section{(2) OpenEdition}

\section{Journals}

\section{Edizione digitale}

URL: http://journals.openedition.org/studifrancesi/7534

DOI: $10.4000 /$ studifrancesi.7534

ISSN: 2421-5856

\section{Editore}

Rosenberg \& Sellier

\section{Edizione cartacea}

Data di pubblicazione: 1 décembre 2009

Paginazione: 614-615

ISSN: 0039-2944

\section{Notizia bibliografica digitale}

Michele Mastroianni, «Aa. VV., Vieillir à la Renaissance, textes réunis, présentés et édités par Colette $\mathrm{H}$. Winn et Cathy Yandell», Studi Francesi [Online], 159 (LIII | III) | 2009, online dal 30 novembre 2015, consultato il 22 janvier 2021. URL: http://journals.openedition.org/studifrancesi/7534; DOI: https:// doi.org/10.4000/studifrancesi.7534

Questo documento è stato generato automaticamente il 22 janvier 2021.

\section{cc) (†) $\odot$}

Studi Francesi è distribuita con Licenza Creative Commons Attribuzione - Non commerciale - Non opere derivate 4.0 Internazionale. 


\title{
Aa. Vv., Vieillir à la Renaissance, textes réunis, présentés et édités par Colette H. Winn et Cathy Yandell
}

\author{
Michele Mastroianni
}

\section{NOTIZIA}

AA. VV., Vieillir à la Renaissance, textes réunis, présentés et édités par Colette H. winN et Cathy YANDELL, Paris, Champion, 2009, «Colloques, congrès et conférences sur la Renaissance européenne» 62, pp. 406.

1 La raccolta di testi organizzata da C.H. Winn e C. Yandell prende per certo avvio da studi fondatori dell'histoire des mentalités quali, nel nostro caso, il lavoro di riferimento di G. Minois (Histoire de la vieillesse en Occident de l'Antiquité à la Renaissance, Paris, Fayard, 1987) ed altri studi che per altro concernono, nella grande maggioranza, il XVIII, il XIX e il xx secolo. La presente raccolta si propone, dunque, di colmare una lacuna, ed anche di confutare dei luoghi comuni circa la percezione della vecchiaia nel Rinascimento, come quelli, per esempio, veicolati dallo stesso Minois, secondo cui il bilancio letterario della vecchiaia nel xvi secolo sarebbe completamente negativo. Ora, «soltanto l'esame di un corpus ampio e svariato - trattati di medicina, opere artistiche e letterarie, e fra queste ultime, ogni tipo di generi, poesia, novellistica, teatro, trattati filosofici, meditazioni religiose, opere morali d'ispirazione satirica, ecc. - può permetterci di cogliere la complessità del pensiero concernente l'invecchiamento $o$ anche l'immaginario nella sua varietas quale fu concepita da un'epoca ricca e brillante come il Rinascimento» (p. 28).

2 I densi contributi qui raccolti, in gran parte concernenti testi letterari, sono i seguenti: Ilana ZINGUER, "Quatrième discours auquel est traicté de la vieillesse...» par André du Laurens 
(1597) (pp. 37-50), Cathy YANDELL, «Le maître qui vieillit»: controverse et vieillissement dans les écrits de Marc-Antoine Muret (pp. 51-67), Jean VIGNES, «Vin vieil, chanson nouvelle donne». La vieillesse dans les proverbes français $d u X I^{e}$ siècle (pp. 69-89), François ROUGET, Ronsard et la vieillesse: expérience et représentation (pp. 93-105), Philip FORD, Ronsard, amant vieillissant dans les «Sonets pour Helene» (pp. 107-117), Catherine MAGNIEN, Étienne Pasquier (1529-1615) ou le vieillard qui n'avait «rien de vieux que l'âge» (pp. 119-144), Marie-Madeleine FRAGONARD, Aubigné ou le triomphe du troisième âge (pp. 145168), Colette H. WINN, «Lors croistra son nom, quoy que la face soit ridée et incongneue». Vieillir au féminin au temps de la Renaissance (pp. 169-187), Gilles BANDERIER, La vieillesse masculine au miroir de la poésie satirique française (pp. 191-206), Hervé-Thomas CAMPANGNE, Vieillards tragiques: figures de la sénescence dans l'histoire tragique "de deux amans, dont l'un mourut de venin, l'autre de tristesse» (pp. 207-219), Madeleine KERN, La vieille femme dans la comédie humaniste française de la Renaissance: entre satire et parodie de clichés (pp. 221-244), Kathleen wILSONCHEVALIER, La mise en image du vieillissement en France à la Renaissance (pp. 245-274), Dora E. POLACHEK, Il faut en rire: Brantôme et le fantasme de la vieille dame érotique (pp. 277-298), Nadine KUPERTY-TSUR, L'idée de la vieillesse dans les mémoires de la Renaissance (pp. 299318), Katherine BANKS, Les mondes nouveau-né et vieillissant: «La Sepmaine» de Du Bartas et la poésie apocalyptique (pp. 319-337), Cynthia SKENAZI, La diversion de la vieillesse: les ruses de Montaigne (pp. 339-357).

Come il titolo stesso della raccolta indica, e come bene sottolineano le curatrici nella densa introduzione (pp. 7-33), il volume non si interessa tanto alla vecchiaia in quanto stato, bensì «al divenire dell'essere, all'evoluzione progressiva di certi segni - fisiologici e psichici - sotto l'effetto del tempo, alle tappe successive che contrassegnano l'invecchiamento» (p. 29). Le quattro sezioni che compongono la raccolta esplorano i diversi aspetti di questo processo. La prima («Le vieillir dans tous ses états») passa in rassegna le idee veicolate dalla cultura dotta e dalla tradizione popolare in modo da contestualizzare la nostra riflessione. La seconda sezione («La vieillesse et son vécu») raccoglie significative testimonianze letterarie (Ronsard, Étienne Pasquier, d'Aubigné) sulla maniera in cui la vecchiaia è stata vissuta dagli uomini e dalle donne del Rinascimento. La terza sezione («Vieilles sorcières et vieux barbons dans l'imaginaire de la Renaissance») si occupa della 'rappresentazione' della vecchiaia, nella satira, nella novellistica e, soprattutto, nel teatro; inoltre, rivolge l'attenzione alle arti figurative. La quarta sezione («La rhétorique du vieillir») evidenzia come il ritratto della vecchia e del vecchio sia ottenuto mediante elaborate strategie retoriche e studia l'uso delle metafore dell'invecchiamento. Questi importanti e interessanti mélanges si concludono con una ricca e utile bibliografia (pp. 359-385). 